Bond University

Research Repository

\title{
Neuropsychological correlates of opioid dependence and withdrawal
}

\author{
Lyvers, Michael; Yakimoff, Michael
}

Published in:

Addictive Behaviors

DOI:

10.1016/S0306-4603(01)00253-2

\section{Licence:}

CC BY-NC-ND

Link to output in Bond University research repository.

Recommended citation(APA):

Lyvers, M., \& Yakimoff, M. (2003). Neuropsychological correlates of opioid dependence and withdrawal. Addictive Behaviors, 28(3), 605-611. https://doi.org/10.1016/S0306-4603(01)00253-2

\footnotetext{
General rights

Copyright and moral rights for the publications made accessible in the public portal are retained by the authors and/or other copyright owners and it is a condition of accessing publications that users recognise and abide by the legal requirements associated with these rights.
}

For more information, or if you believe that this document breaches copyright, please contact the Bond University research repository coordinator. 


\section{Bond University}

\section{ePublications@bond}

January 2003

\section{Neuropsychological Correlates of Opioid Dependence and Withdrawal}

Michael Lyvers

Bond University, Mike_Lyvers@bond.edu.au

Michael Yakimoff

Bond University

Follow this and additional works at: http://epublications.bond.edu.au/hss_pubs

\section{Recommended Citation}

Michael Lyvers and Michael Yakimoff. (2003) "Neuropsychological Correlates of Opioid Dependence and Withdrawal" , .

http://epublications.bond.edu.au/hss_pubs/6 
Neuropsychological Correlates of Opioid Dependence and Withdrawal

\author{
Michael Lyvers \\ Michael Yakimoff \\ Department of Psychology \\ School of Humanities and Social Sciences \\ Bond University \\ Gold Coast, Queensland 4229 Australia \\ telephone: (61) (75) 5952565 \\ facsimile: (61) (75) 5952540 \\ e-mail: mike_lyvers@bond.edu.au
}

\title{
Acknowledgements
}

The study reported here was supported by a grant from the Australian Research Council. We wish to thank all patients who participated in this study as well as Dr. Lynn Hawken and staff of the Gold Coast District Health Service Southside Clinic for their invaluable assistance. 
Alcoholism and other drug addictions are often accompanied by signs of prefrontal cortex dysfunction (see Lyvers, 2000, for a review). Although this evidence is strongest for alcohol and cocaine, the frontal lobes also appear to be a major site of action of opiates such as heroin or morphine (Kuhar, Pert, \& Snyder, 1973; Lewis et al., 1981), and opioid dependence is associated with changes in frontal cortical alpha-2-adrenoceptor function and noradrenaline release (Gabilondo et al., 1994). Brain imaging studies have revealed frontal perfusion deficits in opioid addicts undergoing withdrawal (Krystal et al., 1995; Rose et al., 1996; Van Dyck et al., 1994), consistent with withdrawal-induced hyperactivity of noradrenergic output from locus coeruleus (LC), which inhibits the frontal cortex (Redmond \& Krystal, 1984). Other researchers have observed signs of brain damage in the frontal lobes (Garcia-Sevilla et al., 1997; Liu, Matochik, Cadet \& London, 1998; Pezawas et al., 1998), and neuropsychological indications of frontal lobe dysfunction such as executive cognitive deficits, in opiate addicts (Petry et al., 1998; Strang \& Gurling, 1989).

Previous research by Lyvers and colleagues (Lyvers \& Maltzman, 1991; Lyvers, Maltzman \& Miyata, 1994) has shown that the Wisconsin Card Sorting Test (WCST), a widely used index of executive cognitive functioning, is surprisingly sensitive to the effects of mild psychoactive doses of alcohol or nicotine. Measures of perseveration selectively distinguished drug from placebo or withdrawal conditions; perseveration measures are consistently elevated in persons who have suffered frontal lobe injury (Robinson, Heaton, Lehman, \& Stilson, 1980). The present study compared the acute effects of methadone with short-term methadone deprivation on WCST performance in methadone-dependent patients undergoing methadone maintenance treatment for opiate addiction.

$$
\text { Method }
$$

\section{Participants}

The research participants were 39 right-handed (18 male and 21 female) out-patients 
of the Gold Coast District Health Service Methadone Maintenance Clinic. To qualify for participation, patients had to be $18-45$ years of age $(\underline{\mathrm{M}}=34.1$ years $)$ and stabilized on a 25 $\mathrm{mg}$ or more daily dose of methadone hydrochloride $(\underline{\mathrm{M}}=66.9 \mathrm{mg})$ for at least one month prior to the study. All participants were screened by interview and excluded if they met any of the following criteria: average alcohol consumption exceeding 14 alcoholic drinks per week; recent and continuing administration of any neurologically active drugs other than methadone; prior history of treatment and/or arrest for alcohol or non-opioid illicit drug related problems; major medical conditions; lifetime diagnosis of psychiatric illness. All subjects were paid $\$ 30$ for participating.

\section{Materials}

Severity of Opiate Dependence Questionnaire (SODQ; Sutherland et al., 1986) assesses quantity and pattern of opiate use, physical withdrawal aspects, withdrawal relief drug usage, rapidity of reinstatement after a period of abstinence, history of opiate use, narrowing of drug repertoire, tolerance, and subjective sense of habit severity.

Profile of Mood States (POMS; McNair, Lorr, \& Droppleman, 1971) - a 65-item selfreport measure yielding scores on six mood scales. The five scales assessing negative mood were combined into a unitary construct to form a POMS Distress Index (POMS-DIST; Stanton et al.,1998), and the Vigour scale (POMS-VIG) served to assess subjective arousal.

Wisconsin Card Sorting Test (WCST) - assesses executive-type functions of set maintenance, cognitive flexibility, and ability to inhibit prepotent but incorrect responses. The computerized version of the WCST (Heaton et al., 1993) was used in the present study. Like the manual version, it requires subjects to sort 128 cards on the basis of the color, number, and shape of stimuli depicted on them. People with frontal lobe damage tend to make perseverative responses (PRs) and errors (PEs) (Robinson et al., 1980) on this test. The dual run procedure used in the present study has been shown to increase the sensitivity of the 
WCST to frontal lobe dysfunction (Stuss et al., 1983) and drug effects (Lyvers \& Maltzman, 1991; Lyvers et al., 1994) and more selectively activates the prefrontal cortex than the standard procedure does (Berman et al., 1995; Smith et al., 1997). In recognition of their sensitivity to prefrontal cortex dysfunction (Mountain \& Snow, 1993), the crucial WCST measures in the present study were the percentages of responses that were PEs $(\% \mathrm{PE})$ and PRs (\%PR), with the percentage of responses that were nonperseverative errors (\%NPE) serving as a control index of nonspecific cognitive impairment.

\section{Procedure}

All subjects were tested individually on clinic premises in the same quiet room. They were randomly assigned to two experimental groups. Patients in the early withdrawal group $(\underline{\mathrm{n}}=18)$ were tested prior to receiving their daily dose of methadone, 24 hrs after the last methadone dose. Patients in the recently dosed group $(\underline{\mathrm{n}}=21)$ were tested 90 min after receiving methadone, when drug plasma levels were expected to be high (Ward, Mattick, \& Hall, 1992). Subjects were asked to refrain from consuming alcohol and any other psychoactives, with the exception of tobacco, for $24 \mathrm{hrs}$ prior to the experimental session, and to eat nothing for $3 \mathrm{hrs}$ before testing. They were also asked not to smoke for at least $1 \mathrm{hr}$ before the session. All sessions commenced between $8.00 \mathrm{am}$. and 1.00 p.m.

Upon arrival at the clinic, subjects attested to their compliance with the above requirements in writing prior to testing. They completed the POMS and SODQ, followed by a 10 min tone detection task during which skin conductance responses were recorded (unpublished data). Subjects then performed the computerised version of the WCST in two successive runs. In the first run, the standard instructions were read aloud to participants. Following completion of either all six sorting categories or a maximum of 128 sorting trials, the WCST was performed again, this time with added instructions that specified the sorting criteria. Following completion of both runs, subjects were debriefed, paid and released. 


\section{Results}

Prior to all analyses, data were screened to ensure that statistical assumptions of normality, linearity and, where applicable, homogeneity of variance-covariance were satisfied. All statistical tests were two-tailed. Severity of Opioid Dependence

Participants' SODQ scores ranged from 30 to $81(\underline{\mathrm{M}}=58.2)$, indicating substantial variation in their degree of opioid dependence. For the entire sample, Pearson productmoment correlations were calculated between SODQ scores and WCST measures, as well as mood as assessed by the POMS. Consistent with predictions, SODQ scores were significantly correlated with the crucial second run WCST scores \%PE, $r=.38, p<.05$, and $\% \mathrm{PR}, r=$ $.33, p<.05$. The WCST control measure \%NPE was not correlated with SODQ. POMSDIST correlated significantly with SODQ, $r=.35, p<.05$.

\section{Effects of Methadone Condition on WCST Measures}

As SODQ scores were significantly correlated with crucial WCST variables, analyses of covariance (ANCOVAs), using SODQ score as the covariate, were conducted on the WCST measures, with methadone treatment condition (recently dosed, early withdrawal) as the between subjects factor. For the second run only, significant group differences were indicated on \%PE, $F(1,36)=5.3, p<.05$, and \%PR, $F(1,36)=6.01, p<.05$. Methadone patients in early withdrawal scored significantly higher on $\% \mathrm{PE}(\underline{\mathrm{M}}=8.6)$ and $\% \mathrm{PR}(\underline{\mathrm{M}}=$ 9.1) than did patients who had recently taken methadone (\%PE, $\underline{\mathrm{M}}=7.5 ; \% \mathrm{PR}, \underline{\mathrm{M}}=7.6)$. There was no group difference on the second run control measure \%NPE, $F(1,36)=.03$.

\section{Discussion}

As expected, severity of opioid dependence as assessed by the SODQ was significantly related to crucial second run WCST measures that are specifically sensitive to prefrontal cortex dysfunction. Patients with higher SODQ scores (indicating more severe 
dependence) made relatively more PRs and PEs, and scored higher on the POMs Distress Index. These relationships may reflect deleterious effects of chronic opioid abuse on the frontal lobes, or possibly premorbid deficits. Further, controlling for severity of dependence, methadone patients in early withdrawal exhibited significantly elevated PRs and PEs on the second run of the WCST compared to patients who had received their daily methadone dose, suggesting a mildly disruptive effect of early withdrawal on frontal lobe functioning. Groups did not significantly differ on the control measure of NPEs on the second run of the WCST, further underscoring the apparently selective nature of methadone's effect on cognition. In contrast to the significant second run group differences, there were no group differences in first run WCST performance on any measure, as in previous drug studies cited above.

The present findings resemble those obtained in Lyvers et al.'s (1994) study of nicotine dependent smokers. Lyvers et al. observed a selective performance deficit (more PEs) during nicotine deprivation that was reversed or "normalized" by nicotine intake in heavy smokers. An obvious similarity between the present research and the earlier nicotine study is the common use of drug dependent subjects. Further, a growing body of research suggests that central opioid peptide and noradrenergic circuitry are crucially involved in the expression of abstinence symptomatology during both nicotine and opiate withdrawal (Koob $\&$ Nestler, 1997). The alpha-2-adrenoceptor agonist clonidine, often used to suppress opiate withdrawal symptoms, has also been reported to suppress craving for nicotine in abstinent cigarette smokers (Glassman et al., 1988). LC hyperactivity and resultant excessive norepinephrine release appears to underlie most opiate withdrawal symptomatology (Koob \& Bloom, 1988; Simonato, 1996), and electrical stimulation of the LC in animals inhibits neural activity in the prefrontal cortex (Redmond \& Krystal, 1984). Perhaps the modest cognitive impairing effects of early methadone withdrawal indicated in the present study, and the similar effects of acute nicotine deprivation in heavy smokers, both result from similar 
changes in noradrenergic neurotransmission within the frontal lobes. Chronic drug-induced dysfunction of the mesocortical dopamine system is also likely in both types of dependence (Di Chiara, 1995; Lyvers, 2000; Vezina et al., 1992). The cognitive processes of the frontal cortex are highly sensitive to both dopaminergic and noradrenergic activity (Arnsten, Steere \& Hunt, 1996). Future work should further examine the impact of opioid dependence and withdrawal on various executive cognitive functions mediated by the prefrontal cortex, as such changes are likely to contribute to the disordered behaviors characteristic of addictions.

\section{References}

Arnsten, A. F. T., Steere, J. C., \& Hunt, R. D. (1996). The contribution of $\alpha_{2}$-noradrenergic mechanisms to prefrontal cortical cognitive function. Archives of General Psychiatry, $53,448-455$.

Berman, K. F., Ostrem, J. L., Randolph, C., Gold, J., Goldberg, T. E., Coppola, R., Carson, R.E., Herscovitch, P., \& Weinberger, D. R. (1995). Physiological activation of a cortical network during performance of the Wisconsin Card Sorting Test: A positron emission tomography study. Neuropsychologia, 33, 1027-1046.

Di Chiara, G. (1995). The role of dopamine in drug abuse viewed from the perspective of its role in motivation. Drug \& Alcohol Dependence, 38, 95-137.

Gabilondo, A. M., Meana, J. J., Barturen, F., Sastre, M., \& Garcia-Sevilla, J. A. (1994). $\mu-$ Opioid receptor and $\alpha_{2}$-adrenoceptor agonist binding sites in the postmortem brain of heroin addicts. Psychopharmacology, 115, 135-140.

Garcia-Sevilla, J.A., Ventayol, P., Busquets, X., La Harpe, R., Walzer, C., \& Guimon, J. (1997). Marked decrease of immunolabelled $68 \mathrm{kDa}$ neurofilament (NF-L) proteins in brains of opiate addicts. NeuroReport, $8,1561-1570$.

Glassman, A. H., Stener, F., Walsh, T., Raizman, P., Fleiss, J. L., Cooper, T. B., \& Covey, L. S. (1988). Heavy smokers, smoking cessation, and clonidine: Results of a double-blind, 
randomized trial. Journal of the American Medical Association, 259, 2863-2866.

Heaton, R. K., Chelune, G., Talley, L., Kaz, G., \& Curtiss, G. (1993). Wisconsin Card Sorting Test: Computer Version-2. Odessa, FL: PAR.

Koob, G. F., \& Bloom., F. E. (1988). Cellular and molecular mechanisms of drug dependence. Science, 242, 715-723.

Koob, G. F., \& Nestler, E. J. (1997). The neurobiology of addiction. Journal of Neuropsychiatry \& Clinical Neurosciences, 9, 482-497.

Krystal, J. H., Woods, S. W., Kosten, T. R., Rosen, M. I., \& Seibyl, J. P. (1995). Opiate dependence and withdrawal: Preliminary assessment using single photon emission computerized tomography (SPECT). American Journal of Drug \& Alcohol Abuse, 21, 47-63.

Kuhar, M. J., Pert, C. B., \& Snyder, S. H. (1973). Regional distribution of opiate receptor binding in monkey and human brain. Nature, 245, 447-450.

Lewis, M. E., Mishkin, M., Bragin, E., Brown, R. M., Pert, C. B., \& Pert, A. (1981). Opiate receptor gradients in monkey cerebral cortex: Correspondence with sensory processing hierarchies. Science, 211, 1166-1169.

Liu, X., Matochik, J. A., Cadet, J. L., \& London, E. D. (1998). Smaller volume of prefrontal lobe in polysubstance abusers: A magnetic resonance imaging study. Neuropsychopharmacology, 18, 243-252.

Lyvers, M. (2000). "Loss of control” in alcoholism and drug addiction: A neuroscientific interpretation. Experimental \& Clinical Psychopharmacology, 8, 1-25.

Lyvers, M., \& Maltzman, I. (1991). Selective effects of alcohol on Wisconsin Card Sorting Test performance. British Journal of Addiction, 86, 399-407.

Lyvers, M., Maltzman, I., \& Miyata, Y. (1994). Effects of cigarette smoking and smoking deprivation on Wisconsin Card Sorting Test performance. Experimental \& Clinical 
Psychopharmacology, 2, 283-289.

McNair, D. M., Lorr, M., \& Droppleman, L. F. (1971). Manual for the Profile

of Mood States. San Diego, CA: Educational and Industrial Testing Service.

Mountain, M. A., \& Snow, W. G. (1993). Wisconsin Card Sorting Test as a measure of frontal pathology: A review. Clinical Neuropsychologist, 7, 108-118.

Petry, N. M., Bickel, W. K., \& Arnett, M. (1998). Shortened time horizons and insensitivity to future consequences in heroin addicts. Addiction, 93, 729-738.

Pezawas, L.M., Fischer, G., Diamant, K., Schneider, C., Schindler, S.D., Thurnher, M., Ploechl, W., Eder, H., \& Kasper, S. (1998). Cerebral CT findings in male opioiddependent patients: Stereological, planimetric and linear measurements. Psychiatry Research: Neuroimaging, 83, 139-147.

Redmond, D. E., \& Krystal, J. H. (1984). Multiple mechanisms of withdrawal from opioid drugs. Annual Review of Neuroscience, 7, 443-478.

Robinson, A. L., Heaton, R. K., Lehman, R. A. W., \& Stilson, D. W. (1980). The utility of the Wisconsin Card Sorting Test in detecting and localising frontal lobe lesions. Journal of Consulting \& Clinical Psychology, 48, 605-614.

Rose, J. S., Branchey, M., Buydens-Branchey, L., Stapelton, J. M., Chasten, K., Werrell, A., \& Maayan, M. L. (1996). Cerebral perfusion in early and late opiate withdrawal: A technetium-99m-HMPAO SPECT study. Psychiatry Research: Neuroimaging, 67, 3947.

Simonato, M. (1996). The neurochemistry of morphine addiction in the neocortex. Trends in Pharmacological Sciences, 17, 410-415.

Smith, G., Perdices, M., O’Sullivan, B., Large, M., \& Barrett, N. (1997). PET study of the Wisconsin Card Sorting Test and brain activation correlates of repeated testing. Australian \& New Zealand Journal of Psychiatry, 31 (Supp.), A39. 
Stanton, A. L., Estes, M. A., Estes, N. C., Cameron, C. L., Danoff-Burg, S., \& Irving, L. M. (1998). Treatment decision making and adjustment to breast cancer: A longitudinal study. Journal of Consulting \& Clinical Psychology, 66, 313-322.

Strang, J., \& Gurling, H. (1989). Computerized tomography and neuropsychological assessment in long-term high-dose heroin addicts. British Journal of Addiction, 84, 1011-1019.

Stuss, D. T., Benson, D. F., Kaplan, E. F., Weir, W. S., Naeser, M. A., Leiberman, I., \& Ferrill, D. (1983). The involvement of orbitofrontal cerebrum in cognitive tasks. Neuropsychologia, 21, 235-248.

Sutherland, G., Edwards, G., Taylor, C., Phillips, G., Gossop, M., \& Brady, R. (1986). The measurement of opiate dependence. British Journal of Addiction, 81, 485-494.

van Dyck, C. H., Rosen, M. I., Thomas, H. M., McMahon, T. J., Walllace, E. A., O’Connor, P. G., Sullivan, M., Krystal, J. H., Hoffer, P.B., Woods, S. W., \& Kosten, T. R. (1994). SPECT regional blood flow alterations in naltrexone-precipitated withdrawal from buprenorphine. Psychiatry Research: Neuroimaging, 55, 181-191.

Vezina, P., Blanc, G., Glowinski, J., \& Tassin, J. (1992). Nicotine and morphine differentially activate brain dopamine in prefrontocortical and subcortical terminal fields: Effects of acute and repeated injections. Journal of Pharmacology \& Experimental Therapeutics, $261,484-490$.

Ward, J., Mattick, R. P., \& Hall, W. (1992). Key issues in methadone maintenance treatment. Kensington, NSW: New South Wales University Press. 